\title{
CORPORATIVISMO HISTÓRICO NO BRASIL E NA EUROPA
}

http://dx.doi.org/10.15448/1980-864X.2016.2.22508

\section{Elites políticas e intelectuais e o Ministério do Trabalho - 1931/1945*}

\author{
Political and intellectual elites and the \\ Ministry of Labour - 1931/1945 \\ Elites políticas e intelectuales y el \\ Ministerio del Trabajo - 1931/1945
}

Francisco Carlos Palomanes Martinho**

Resumo: O presente artigo tem por objetivo analisar o processo de criação do Ministério do Trabalho, Indústria e Comércio no Brasil (1931), bem como o papel desempenhado pelas elites políticas e intelectuais que nele participaram, auxiliando no projeto de institucionalização do mundo do trabalho ocorrida durante o primeiro governo Vargas (1930-1945).

Palavras-chave: corporativismo; intelectuais; Ministério do Trabalho

Abstract: This paper aims to examine the process of establishment of the Ministry of Labour, Industry and Commerce in Brazil (1931), as well as the role played by the political and intellectual elites that conduced it, helping on the project of institutionalization of the "world of labour" during Vargas' first government (1930-1945).

Keywords: corporatism; intellectuals; Ministry of Labour

Resumen: El presente artículo tiene por objetivo la análisis del proceso de creación del Ministerio del Trabajo, Industria y Comercio en Brasil (1931), bien como el papel desempeñado a través de las elites políticas e intelectuales que en él participaban, auxiliando en el proyecto de institucionalización del mundo del trabajo durante el primer gobierno Vargas (1930-1945).

Palabras claves: corporativismo; intelectuales; Ministerio del Trabajo

\footnotetext{
*Pesquisa realizada com o apoio do Conselho Nacional de Desenvolvimento Científico e Tecnológico (CNPq).

**Professor Livre-docente do Departamento de História da Universidade de São Paulo e pesquisador do CNPq. <fcpmartinho@usp.br>< <ados biográficos/biographic data>
} 


\section{Introdução}

Chamado pelo presidente Getúlio Vargas de "O Ministério da Revolução", o Ministério do Trabalho, Indústria e Comércio, criado logo após a Revolução de 1930, teve papel fundamental nas novas diretrizes adotadas pelo Estado no sentido da institucionalização e regulamentação do mundo do trabalho. Como ministros, assessores ou apenas consultores, dele participaram alguns dos mais destacados representantes das elites formadoras de opinião e dotadas de poder decisório no país. O papel desses agentes era, sobretudo, o de apresentar um projeto para o Brasil que se diferenciasse do passado liberal e federalista que tanto caracterizaram a Primeira República brasileira. $\mathrm{Na}$ ideia de ruptura para com o passado, um outro olhar sobre o Estado e a Nação eram também apresentados. O trabalho, considerado um valor fundamental para a obtenção da cidadania entre as chamadas "classes subalternas", inexistente até a Primeira República, era um dentre tantos os vetores que conduziriam o Brasil para um "novo" tempo histórico (GOMES, 1991; GOMES, 2000; GOMES, 2002b, p. 384-437).

Podemos afirmar que as elites aqui discutidas configuram aquilo que Norberto Bobbio classificou de expertos, por um lado, e ideólogos, por outro. Em outras palavras, enquanto alguns atuavam como agentes do Estado, outros destacavam-se de forma autônoma, independentes que eram de qualquer vínculo institucional com os novos aparelhos burocráticos criados no pós-1930 (BOBBIO, 1997, p. 67-90). Ou, para utilizarmos os conceitos consagrados por Jean-François Sirinelli, estamos a falar de criadores e mediadores, ou seja, tanto aqueles empenhados em articular a produção do conhecimento, quanto os "atores" engajados no jogo político (SIRINELLI, 1986). No caso brasileiro, na ausência de um partido à moda nacional-socialista ou fascista, a origem destas elites era, por certo, mais diversa e plural (PINTO, 2002, p. 161-186). Das velhas oligarquias oriundas da Primeira República até as elites sindicais, passando por setores das classes médias, as elites governamentais do primeiro governo Vargas, ajudaram a inaugurar uma fase da História republicana brasileira ancorada em uma dinâmica política que tinha o Estado como o agente impulsionador das transformações vividas à época (FONSECA, 2012, p. 159-178).

$\mathrm{O}$ presente artigo está dividido em três partes. Na primeira procura-se fazer uma breve apreciação do debate historiográfico acerca do que representou o período compreendido entre a Revolução de 1930 e o golpe do Estado Novo. Na segunda parte é analisado o papel 
desempenhado pelos primeiros ministros do Trabalho na consolidação do chamado "ministério da Revolução". Por fim, a terceira parte é dedicada às novas elites que ocuparam cargos de assessores do Ministério e o papel destes na institucionalização das relações laborais no Brasil.

\section{Da Revolução de 1930 ao Estado Novo: bonapartismo, modernização pelo alto ou pacto entre as elites?}

A ditadura corporativa instaurada no Brasil a partir de 1937 - o Estado Novo - é fruto de um processo que combina uma redefinição dos parâmetros institucionais vigentes no país até então e a resolução, passo a passo, de crises políticas vividas pelo governo que se apossou da República em outubro de 1930. Quanto ao primeiro caso, podemos citar o processo constituinte de 1933-34, cujo resultado desagradou profundamente a Vargas e ao staff de seu governo (GOMES, 1994, p. 159-162). O modelo institucional desejado viria, então, com o golpe do Estado Novo. No que concerne à superação de crises, o exemplo mais evidente foi o enfrentamento da esquerda organizada na Aliança Nacional Libertadora, seu fechamento e a consequente outorga da Lei de Segurança Nacional em 1935 que, no dizer de Luís Werneck Vianna foi a antecipação do Estado Novo para os trabalhadores organizados (VIANNA, 1978, p. 199) ${ }^{1}$. Observação curiosa esta que reduz a política da classe trabalhadora à sua dimensão organizacional e/ou corporativa. A repressão contra a direita fascista, a Ação Integralista Brasileira e seu consequente fechamento ocorreu apenas em 1938, já sob o regime do Estado Novo (TRINDADE, 1986, p. 297-335). Criava-se, assim, uma nova ordem ao mesmo tempo centralizadora e modernizadora ao mesmo tempo em que excluía, ou pretendia excluir, segmentos situados ideologicamente em campos considerados extremos para o novo regime.

A Revolução de 1930, responsável pela alteração política nos rumos de uma República, instaurada pouco mais de quarenta anos antes, trouxe, como primeira novidade, a incorporação de segmentos sociais até então completa ou parcialmente alijados da participação no poder público. Ao mesmo tempo, entretanto, não deixou de manter entre seus quadros dirigentes representantes da velha ordem. Dentre os "novos", podemos citar as camadas médias e intelectualizadas dos principais centros urbanos, os grupos militares de baixa patente e a classe trabalhadora urbana, incorporada através da legislação social

${ }^{1}$ Sobre o tema, em outra perspectiva analítica, ver também: (VIANNA, 1992) 
que se elaborou a partir da criação do Ministério do Trabalho, Indústria e Comércio. Dentre os "velhos", além da antiga oligarquia agrária, hegemônica na República desde a Constituição Liberal de 1891, que se dividiu com os acontecimentos de 1930, devemos também citar as elites industriais e a alta hierarquia militar, responsável pela queda da Monarquia em 1889 (FAUSTO, 1989; 1988, p. 06-37). Podemos ainda citar uma representativa geração de advogados que, oriundos das elites agrárias decadentes, procuraram na formação profissional um caminho para a preservação de algum status político e dirigente (PINHEIRO, 1985, p. 7-37).

A "ampliação" do quadro político e social inaugurado em 1930 provocou diversos debates a respeito da natureza do regime que se estabeleceu entre a Revolução e o golpe do Estado Novo em 1937. Se para uns tratava-se de uma espécie de bonapartismo, na medida em que assim como em Luiz Bonaparte, ao chefe de governo era dada uma autonomia de gerência e direcionamento político em relação às classes sociais (RODRIGUES, 1986, p. 532-533), para outros tratava-se de uma "revolução pelo alto" (VIANNA, 2001, p. 111-153), à moda prussiana e responsável por uma modernização de tipo autoritária no país. Para além dessas análises acerca da natureza do Estado, uma terceira corrente surgida em trabalhos mais recentes aponta para a constituição de um pacto entre grupos diferenciados, com maior ou menor grau de influência no direcionamento político e institucional do país (GOMES, 1999, p. 53-72).

A possibilidade de real implementação do pacto se deu em decorrência da também real ampliação da importância e poder decisório dos grupos sociais emergentes, bem como das elites que representavam esses grupos. No caso do sindicalismo brasileiro, as mudanças ocorridas nos anos 30 saltam aos olhos. Em primeiro lugar, a legislação que criou os sindicatos oficiais criou também um imposto compulsório, que era a cobrança de um dia de serviço de cada trabalhador, fosse ele sindicalizado ou não. Este dinheiro ia para a estrutura burocrática e administrativa arquitetada pelo Estado: do Ministério do Trabalho aos sindicatos propriamente ditos, passando por federações e confederações (RODRIGUES, 1986, p.511-513). Embora reconhecendo as dificuldades em calcular em números exatos os novos dirigentes sindicais, Leôncio Martins Rodrigues lembra que, ao final do Estado Novo, havia 873 sindicatos de trabalhadores registrados no Ministério do Trabalho. Se imaginarmos que em cada um desses sindicatos havia cerca de dez dirigentes liberados do trabalho, então a camada de burocratas compreenderia cerca de 
nove mil membros. Entretanto, ao aparato sindical propriamente dito, devem ser contabilizados uma série de profissionais a ele direta ou indiretamente vinculados: advogados trabalhistas, médicos, enfermeiros, dentistas, contadores, funcionários de escritório, motoristas, pessoal de limpeza, etc, todos eles financiados com os recursos do imposto sindical. Não se trata de um contingente desprezível, embora seja difícil contabilizar a totalidade destes profissionais (RODRIGUES, 1986, p. 528-529). E atentemos para o fato de que não foram calculados aqui os profissionais que foram trabalhar nas federações, confederações ou no próprio Ministério do Trabalho.

\section{Os Ministros - entre "velhas" e "novas" elites}

Além do crescimento vertiginoso de funções decorrentes do aumento da estrutura burocrática do Ministério, vale destacar aqui a importância de quadros políticos que atuaram na máquina estatal dando suporte teórico na condução das políticas sociais e corporativas. Dentre os Ministros que ocuparam a pasta do Trabalho durante o primeiro governo Vargas, podemos dizer que prevaleceram aqueles oriundos das "velhas" elites que, por força das circunstâncias, modernizaram-se e foram responsáveis pela implantação do projeto reformista de Estado.

O primeiro, Lindolpho Collor, pertence ao grupo de políticos gaúchos que acompanhou Getúlio Vargas desde o início de sua carreira. Segundo Alfredo Bosi, trata-se de uma geração de políticos profundamente influenciada pelo positivismo social que, tendo se tornado hegemônica no Rio Grande durante a Primeira República, adotou, a partir de 1930, a mesma política de "Estado providência" em âmbito nacional. Uma política ancorada no controle social, na centralização administrativa e na busca de harmonia entre as classes (BOSI, 1992, p. 273-307). Primeiro ministro do "Ministério da Revolução", Collor afirmava que no pouco tempo em que ocupou o cargo, um ano e três meses, ajudou a dotar o Brasil de algumas leis "fundamentais" inexistentes até então: aposentadoria e pensão aos servidores públicos, sindicalização das classes, entendendo os sindicatos como colaboradores do Estado, jornada de oito horas de trabalho, proteção das mulheres e crianças, convenções coletivas e comissões mistas de conciliação, entre outras (COLLOR, s/d, p.30). Dentre as leis citadas pelo ex-ministro, vale citar duas de importância crucial para as relações de trabalho no Brasil ancoradas na ótica do corporativismo: a sindicalização obrigatória entendida como canal de colaboração com o Estado, e não mais de conflito como predominou na 
Primeira República (FAUSTO, 1976; BATALHA, 2003, p. 161-189), e as comissões mistas entre Estado, trabalhadores e patrões, novidade que veio a desagradar profundamente os últimos, acostumados que estavam a agirem sem a tutela estatal (GOMES, 1979, p. 199-252). Embora breve sua passagem pelo Ministério, a legislação inaugurada por Collor permaneceu, assim como a maior parte das leis elaboradas pelos ministros que vieram a seguir. Legislação, aliás, que se manteve em larga medida até a Constituição de 1988. Não cabe, por força do tema do presente artigo e do espaço de que dispomos discutir o quanto desta legislação se mantém ainda hoje, em pleno século XXI. Mas apenas o exemplo do monopólio de representação territorial dos sindicatos, que permanece ainda hoje, como também a inclusão das centrais sindicais que passaram recentemente a receber o butim do imposto sindical, é demonstrativa de que a legislação do trabalho inaugurada no início da década de 1930 se mantém com força e relativa estabilidade. No caso das centrais sindicais, ao invés de se manterem autônomas, como era de sua tradição, procuraram - e encontraram - o abrigo no Estado em tempos de neocorporativismo (MARCANTE, 2014, p. 267-287).

A saída de Collor levou Vargas a escolher, como novo chefe da pasta do Trabalho, o também gaúcho Joaquim Pedro Salgado Filho. Formado em direito pela Faculdade Livre de Direito do Rio de Janeiro, pai militar, foi adepto da Revolução de 1930, ocupando cargos junto à Polícia do Distrito Federal até ser nomeado Ministro em abril de 1932. Foi sob sua gestão que foram criados a Carteira Profissional e os Institutos de Aposentadorias e Pensões, responsáveis pela inauguração de uma nova política previdenciária no país (MOREIRA, s/d). A unificação da previdência social no Brasil veio a ocorrer apenas quando do regime civil-militar, com a criação do Ministério da Previdência e Assistência Social, na feliz expressão de Ângela de Castro Gomes, o "Ministério da Revolução de 1964" (GOMES, 2002a, p. 121-148). A entrada de Salgado Filho no Ministério, aliada à derrota da Revolução Constitucionalista de 1932, marca uma fase de efetivo esforço no sentido da "real aplicação das leis sociais", razão pela qual se viu obrigado a enfrentar permanentes objeções por parte do patronato (GOMES, 1979, p. 224-225). A despeito da promulgação de diversas leis e da inequívoca fidelidade a Vargas, Salgado Filho retirou-se de Ministério ao ser eleito deputado classista para a legislatura que teria início em 1935.

Foi substituído pelo pernambucano Agamenon Magalhães. Filho de um tradicional político de seu Estado, aliado do Marechal Hermes da Fonseca, formou-se em direito pela Faculdade de Direito do Recife. 
Apoiou o movimento revolucionário de 1930 e foi eleito deputado constituinte por Pernambuco e depois indicado pelo interventor deste Estado ao cargo de Ministro do Trabalho (PANTOJA, s/d). Defensor da unicidade sindical mostrou-se profundamente insatisfeito com os resultados da constituinte que havia aprovado, ainda que com restrições, o princípio da pluralidade (GOMES, 1994, p. 159). Mas seu papel mais importante na gestão do Ministério foi no sentido da manutenção da ordem pública. A Lei de Segurança Nacional e o Tribunal de Segurança Nacional, criados neste o período alteraram significativamente o sentido das relações entre Estado e trabalhadores no Brasil. Não é fato que enquanto que a questão social na Primeira República foi um "caso de polícia”, após 1930 ela teria se transformado em política de Estado. Esta visão reducionista ignora o papel dos agentes sociais que, durante o início da experiência republicana empenharam-se pela construção de um "mundo do trabalho" com efetivos canais de negociação com os poderes públicos (GOMES, 1994, p. 161; MARTINHO, 2002, p. 199-240). Ao mesmo tempo, não negamos o aparecimento de importantes alterações nas relações Estado-trabalhadores. Em tese, ao primeiro caberia confecção do benefício através da legislação social. Aos trabalhadores cabia, a obediência (GOMES, 2007, p. 79-207).

O golpe do Estado Novo em 1937 levou Agamenon Magalhães ao cargo de interventor no Estado de Pernambuco (PANDOLFI, 1984). O indicado para sucedê-lo foi Valdemar Falcão, filho de família tradicional do Estado do Ceará e formado pela Faculdade de Direito daquele Estado. Teve larga experiência como político e também como professor, tanto da Faculdade como do Colégio Militar do Ceará. Após a Revolução de 1930, ocupou importantes cargos, dentre os quais a vice-presidência do Conselho Nacional do Trabalho. Eleito deputado constituinte, defendeu a Justiça do Trabalho, criada com a Revolução de 1930 e que contava com forte oposição dos segmentos mais conservadores das elites agrárias e industriais. ${ }^{2}$ Eleito senador em 1935, destacou-se no combate ao comunismo, chegando mesmo a ser apontado como defensor da fascistização do país. Indicado Ministro do Trabalho após o golpe do Estado Novo, Valdemar Falcão regulamentou o salário mínimo e a Justiça do Trabalho, tendo sido designado Ministro do Supremo Tribunal Federal em 1941, quando deixou o Ministério (FALCÃO, s/d). A atuação de Valdemar Falcão no Ministério do Trabalho representa bem a combinação do reformismo modernizante aliado à centralização

\footnotetext{
${ }^{2}$ Sobre a Justiça do Trabalho e suas múltiplas facetas, ver: (GOMES; SILVA, 2013)
} 
administrativa que se inaugurou no Brasil em 1930 e que foi aprofundada quando do golpe do Estado Novo em 1937.

A saída de Falcão do Ministério do Trabalho coincidiu com o período em que o Brasil, por razões de cunho pragmático e em decorrência de pressões internas, assinalava uma aproximação com o bloco aliado na Segunda Guerra Mundial. A Constituição de 1934 instituiu eleições diretas para presidente da República, mas estabeleceu que o primeiro presidente fosse eleito pelos próprios constituintes. Vargas, desse modo, foi eleito presidente e novas eleições estavam previstas para quatro anos depois. O golpe do Estado Novo adiou sine die o processo. Entretanto, sabia-se que o retorno à democracia era uma questão de tempo, e a opção do Brasil mais que evidenciava este caminho. Assim, a escolha de Alexandre Marcondes Filho como novo Ministro do Trabalho, obedeceu à necessidade de implementar uma política de mobilização que garantisse a permanência de Vargas em um sistema democrático. A este esforço de mobilização, Ângela de Castro Gomes chamou de "invenção do trabalhismo" (GOMES, 1994, p. 195-219). Formado pela Faculdade de Direito de São Paulo, foi deputado pelo tradicional Partido Republicano Paulista e opositor de Vargas no início de seu governo. Aproximou-se do regime quando da imposição do Estado Novo, participando primeiro como vice-presidente do Departamento Administrativo do Estado de São Paulo, órgão responsável por aprovar empreendimentos e decretos da administração estadual, e depois, a partir de dezembro de 1941, como Ministro do Trabalho. Vale destacar também que entre 1942 e 1945, Marcondes Filho acumulou os cargos de Ministro do Trabalho e da Justiça (MAYER, s/d). A partir de sua gestão, podemos identificar um remanejamento da política trabalhista do Estado brasileiro. Novas diretrizes foram traçadas e novas estratégias políticas utilizadas. No período anterior, após a Revolução de 1930, foram elaboradas diversas leis trabalhistas, fazendo com que o Brasil viesse a dar um enorme salto no que diz respeito à legislação social.

Durante seu ministério houve uma intensificação da relação do Estado com os trabalhadores em geral, sendo ele o mediador desta relação. Marcondes Filho enfatizou a importância da organização sindical, e elaborou uma forte política de propaganda com objetivo de promover e divulgar a legislação trabalhista que estava sendo estruturada e aprofundada, além de buscar estreitar os laços entre trabalhadores e Estado. Estas são as bases da chamada ideologia do trabalhismo que se constituiu deste então. Marcondes Filho foi um dos principais encarregados de pôr em prática estas estratégias: solidificar as diretrizes 
do Estado Novo e também exaltar a figura de Getúlio Vargas. Dentre as estratégias utilizadas por ele e pelo DIP (Departamento de Imprensa e Propaganda) para a realização destes objetivos destacaremos duas. Em primeiro lugar, a transmissão radiofônica de programas estatais voltados aos trabalhadores, priorizando o esclarecimento e a difusão das recém-criadas leis sociais, principalmente o programa "Hora do Brasil", no qual Marcondes Filho palestrava semanalmente. E em segundo lugar, a promoção de festas e comemorações nas celebrações de datas nacionais importantes: entre outras, o aniversário de Getúlio Vargas (19 de abril), o Dia do Trabalho (1ㅇ de maio), o aniversário da Revolução de 1930 (3 de outubro) e o aniversário do Estado Novo (10 de novembro) (MARTINHO; BESKOW, 2002). Foi também através do Ministério do Trabalho que neste período se organizou o Partido Trabalhista Brasileiro, espelhando que o retorno à democracia era inevitável. De feição reformista, pretendia dar continuidade à política social inaugurada com a Revolução de 1930, no âmbito do parlamento e através do jogo eleitoral (GOMES, 1994, p. 249-281; DELGADO, 1989; D’ARAÚJO, 1996).

\section{O Ministério e seus assessores - reformismo, modernização e Estado de Bem Estar}

Diversos foram os assessores que trabalharam no sentido de dar uma conotação moderna e reformista ao Ministério do Trabalho, Indústria e Comércio. Na impossibilidade de referirmo-nos a todos, destacaremos alguns que consideramos especialmente importantes: Oliveira Viana, Evaristo de Moraes e José de Segadas Viana.

Francisco José de Oliveira Vianna (ABREU, 2013, p. 91-121; VENÂNCIO, 2015) não foi exatamente um assessor do Ministério do Trabalho, posto que não ocupava cargo naquela instituição. Filho da pai fazendeiro e coronel da Guarda Nacional, fez seus estudos no Colégio Pedro II e bacharelou-se pela Faculdade Nacional de Direito, no Rio de Janeiro. Responsável por vasta obra bibliográfica, destacou-se como um dos mais importantes expoentes do pensamento nacionalista autoritário no Brasil, ao lado de Francisco Campos e Antônio José de Azevedo Amaral (FAUSTO, 2001, LAMOUNIER, 1985, p. 343-374). Foi, entretanto, importante formulador de ideias seguidas não só pelo Ministério do Trabalho, como também pelo regime como um todo. Apoiou o Estado Novo em primeira mão, não hesitando em defender um modelo centralizador em torno da figura do Presidente da República: 
Do que precisamos é de um Presidente único. Isto é, do Presidente que não divida com ninguém sua autoridade; do Presidente soberano, exercendo, em suma, seu poder em nome da Nação, só a ela subordinado e só a ela dependente (VIANA, 1927).

Ao mesmo tempo, procurou sempre demarcar a defesa de um modelo autoritário dos regimes chamados "totalitários" alemão e italiano:

Não há em nosso povo, na sua psicologia coletiva, condições para a constituição de uma mística viva e orgânica, uma mística que se apodere da alma nacional e a mova em um sentido nitidamente determinado, para um objetivo preciso - como o nacionalismo imperialista dos italianos de Mussolini ou o nacionalismo racista dos alemães de Hitler. Uma pequena coorte ou falange de homens de elite poderá, aqui, tomar-se de uma mística e agir no sentido dela; não um partido, mesmo que ele represente uma minoria da Nação e seja o único partido militante (VIANA, 1927).

O breve trecho de Oliveira Viana mostra ao mesmo tempo sua vocação elitista e seu profundo desprezo pela democracia liberal. Segundo importante estudioso de sua obra, as concepções corporativas que deram norte a seu pensamento são fruto da conjugação de três importantes fatores: a vocação corporativa brasileira, herança do passado colonial e do Império, que demarca da tradição liberal europeia; a ojeriza pessoal quanto à inoperância do sistema parlamentar e a necessidade de o Estado impor-se frente à incapacidade da população brasileira de organizar-se autonomamente. Para Oliveira Viana, a solução corporativa foi a única capaz de construir uma verdadeira democracia. Uma democracia orgânica, e não aquela fragmentária típica do passado liberal vigente na Primeira República (VIEIRA, 1981, p. 103-133). Fiel a seus princípios corporativos, quando da queda do Estado Novo e do retorno à democracia liberal-parlamentar, Oliveira Viana preservou sua profunda oposição ao sistema liberal por considerá-lo incapaz de atender às demandas do mundo moderno. Mais que isso, manteve-se firme na convicção da necessidade, como um imperativo categórico kantiano, da intervenção estatal (ABREU, 2013, p. 121).

Se Oliveira Viana não foi exatamente um funcionário do Ministério do Trabalho, mas sim um jurista que serviu como uma referência teórica para aquela instituição, o mesmo não se pode dizer de Evaristo de Moraes (MENDONÇA, 2007). Mestiço e filho de classe média, estudou como bolsista do Colégio São Bento. Quando o pai abandonou 
a família, teve que interromper seus estudos para trabalhar. Bacharelouse em direito já com 45 anos. Foi, durante a Primeira República, um importante tribuno dos movimentos populares. Militante socialista foi preso duas vezes durante a presidência de Artur Bernardes. Amigo de Lindolpho Collor foi convidado a exercer a função de consultor jurídico do Ministério. Defensor da nacionalização do trabalho ajudou a elaborar o Decreto-Lei no 19.482, que instituiu a obrigatoriedade das empresas em manterem em seus quadros $2 / 3$ de brasileiros natos. Com a colaboração do também jurista Joaquim Pimenta, elaborou o DecretoLei no 19.770, que regulamentou a sindicalização de empregados e patrões, além de ter contribuído também na imposição da unicidade sindical, reformando o modelo estabelecido de pluralidade vigente na Primeira República. Entusiasta da criação do Ministério do Trabalho e da legislação trabalhista, sobre ela escreveu:

Collor resistiu às incursões atrevidas de certas empresas que pretenderam influir na actividade legislativa do Ministério moldando-a pelos interesses capitalísticos. Continuou firme a resistência com o novo ministro. E ninguém ignora que começada sob a antiga administração, permanece, diariamente, na imprensa, a campanha dos despeitados, visando, antes de tudo, as leis de sindicalização e aposentadorias e pensões. (...). Anteriormente poucas leis mostraram a preocupação dos governantes com os problemas sociais e trabalhistas. A mais recente era a dos infortúnios do trabalho, decretada em 1919, cheia de graves imperfeições. O descaso oficial chegou ao ponto de nunca ter sito executada uma lei, 'de 1891', relativa ao trabalho das crianças nas fábricas (MORAES, s/d, p. 67-68).

É interessante notar que a legislação corporativa que se inaugurava no Brasil teve um antigo e destacado expoente do embrionário pensamento socialista brasileiro como um dos seus mais importantes arquitetos. A presença, inédita, de um Estado disposto a regular o mundo do trabalho não deixou de entusiasmar uma parcela considerável das elites intelectuais de esquerda surgidas ao longo da primeira experiência republicana brasileira. Ao mesmo tempo, e contraditoriamente, é necessário dizer que, ao lado dessas elites que poderiam ser chamadas de progressistas, também aderiram ao regime instaurado a partir de 1930 segmentos simpáticos ao fascismo e a outras formas de manifestação ideológica. A unificá-los, apenas a convicção da necessidade de se elaborar e aplicar um conjunto, novo e amplo, de leis sociais no país (GOMES, 1994, p. 148). 
A legislação trabalhista inaugurada em 1930 com Lindolpho Collor e Evaristo de Moraes teve seu coroamento em 1943 na gestão de Alexandre Marcondes Filho, através da Consolidação das Leis do Trabalho. A CLT, como ficou conhecida, não é exatamente uma legislação nova, mas a junção de todas as leis referentes ao trabalho inauguradas a partir da Revolução de 1930 (FRENCH, 2001). Dentre os quadros apontados pelo Ministro para elaborar a CLT sobressai o nome de José de Segadas Viana. Formado pela Faculdade de Direito do Rio de Janeiro, foi promotor público antes de ingressar na política como membro da Aliança Liberal que levou Getúlio Vargas a candidatar-se à Presidência da República. Afastou-se posteriormente do governo, vindo a trabalhar como jornalista. Em 1940, passou à condição de procurador da Justiça do Trabalho. Dois anos depois, a convite de Marcondes Filho, assumiu o cargo de assistente técnico do Ministério do Trabalho. Na condição de funcionário do Ministério, foi um dos principais articuladores da criação do Partido Trabalhista Brasileiro. Para a organização deste partido, que viria a se constituir como principal base de sustentação da herança getulista junto aos trabalhadores urbanos em tempos de democracia, foi fundamental a estrutura montada pelo Ministério para a constituição dos sindicatos oficiais. O que pretendiam os organizadores do PTB era a formação de um partido reformista à semelhança do Partido Trabalhista Britânico ${ }^{3}$. No início, inclusive, chegou-se mesmo a ser aventada a possibilidade de um partido que unificasse todas as elites políticas vinculadas a Vargas. Segmentos de feição mais conservadora trataram, entretanto, de inviabilizar tal proposta. Assim é que, dos setores que no Estado Novo apoiaram Vargas, nasceram dois partidos: o já citado PTB, vinculado ao Ministério do Trabalho e à burocracia sindical, e o PSD (Partido Social Democrático), vinculado às elites agrárias localizadas nas interventorias dos Estados e à alta hierarquia das Forças Armadas (HIPÓLITO, 1984). O papel de Segadas Viana foi fundamental como articulador da aproximação dos sindicatos oficiais ao PTB na medida em que ocupava as Comissões de Enquadramento Sindical e de Técnica de Orientação Sindical, através das quais impôs um rígido processo de filiação ex ofício àquele partido (KORNIS, $\mathrm{s} / \mathrm{d}$ ). Para o processo histórico de formação de um Brasil moderno é justo e necessário afirmar que foram estes novos atores, princi-

\footnotetext{
${ }^{3}$ Enquanto Ângela de Castro Gomes e Maria Celina D'Araújo apontam a criação do PTB como um projeto de Estado decorrente da necessidade de dar continuidade à política social-trabalhista, Lucília de Almeida Neves vê a criação deste partido como uma tentativa de anteparo frente ao crescimento do Partido Comunista do Brasil, recém posto na legalidade. Ver obras citadas.
} 
palmente localizados junto ao Ministério do Trabalho, Indústria e Comércio, os responsáveis pela condução de uma política reformista cuja construção do Partido Trabalhista Brasileiro é apenas o exemplo mais evidente.

\section{Conclusão}

As mudanças políticas inauguradas no Brasil a partir da Revolução de 1930 impulsionaram o país no sentido da modernidade. Coube às elites dirigentes que se apoderaram do poder político à época implementar uma eficaz industrialização, combinada à adoção de um corpo legislativo até então inédito. Como inédita, também, foi a criação do Ministério do Trabalho, Indústria e Comércio. No bojo das transformações vividas, vale destacar a incorporação à cidadania pública de amplos segmentos que até então tinham pouca ou nenhuma ingerência nas questões da esfera pública. Estas mudanças podem ser verificadas mesmo no âmbito da alta hierarquia ministerial. A presença majoritária de bacharéis evidenciou um país que, lentamente, saía do campo para a cidade. As Faculdades de Direito, assim como as Forças Armadas, foram lugar privilegiado de ocupação por parte de representantes de elites agrárias que começavam a entrar em decadência. Na escala intermediária, pudemos notar também, a presença de advogados oriundos algumas vezes de camadas populares ou de classes médias empobrecidas. Por fim, deve-se salientar que, se pensarmos a estrutura ministerial como um todo, incluindo neste caso os sindicatos oficiais, o que chamamos de "elites" se amplia consideravelmente. O sindicalismo deixou de ser, com a outorga da legislação social, uma atividade perigosa e até subversiva, para transformar-se em algo que oferecia prestígio e reconhecimento. Além de tantas profissões criadas pelo Estado no pós 30, uma outra, paralela e informal, se impunha: a profissão de sindicalista.

Se atentarmos para o fato de que o Governo Vargas teve seu início a partir de um golpe de Estado, poderemos então perceber o papel de descontinuidade com relação ao período anterior. As políticas social, de industrialização e de intervenção estatal também evidenciam esta descontinuidade. Entretanto, se o caráter de ruptura não deve ser questionado, também não se pode desconsiderar os aspectos característicos da continuidade. Parte majoritária das elites que fizeram parte de seu governo tinham, no mínimo, alguma participação política na Primeira República, mesmo que no papel de oposição. Assim, à guisa 
de comparação, a experiência corporativa brasileira guarda diferenças importantes se compararmos ao caso português, onde a grande maioria da elite ministerial de Salazar tinha pouca ou nenhuma participação política anterior (PINTO, 2002, p. 164-165). Ao mesmo tempo, na medida em que o Estado Novo brasileiro se encerrou em 1945, vale lembrar que o caráter de continuidade se manteve, uma vez que parcelas consideráveis daquelas elites que compunham o regime deposto se mantiveram no poder sob o regime democrático-constitucional que se iniciava. O próprio Presidente Vargas, embora formalmente afastado da política, elegeu-se Senador pelo Rio Grande e em 1950 retornou eleito à presidência da República (GOMES, 1994, p. 249-281; SOUZA, 1983). Quanto às elites localizadas no Ministério do Trabalho, e que desempenharam papel determinante na implementação e elaboração de novas diretrizes às políticas social e trabalhista no Brasil, elas se mantiveram ativas nos anos de 1945 a 1964, quando outras rupturas e continuidades voltaram à cena na história política brasileira.

\section{Referências}

ABREU, Luciano A. Sindicalismo e corporativismo no Brasil: o olhar autoritário de Oliveira Vianna. In: ABREU, Luciano Arrone; MOTTA, Rodrigo Patto Sá (Orgs.). Autoritarismo e cultura política. Rio de Janeiro: FGV; Porto Alegre: EDIPUCRS, 2013. p. 91-121.

BATALHA, Cláudio. Formação da classe operária e projetos de identidade coletiva. In: FERREIRA, Jorge; DELGADO, Lucília de Almeida Neves (Orgs.). O Brasil Republicano: O tempo do liberalismo excludente - da proclamação da República à Revolução de 1930. Rio de Janeiro: Civilização Brasileira, 2003. p. 161-189.

BOBBIO, Norberto. Os Intelectuais e o Poder. Dúvidas e opções dos homens de cultura na sociedade contemporânea. São Paulo: Unesp, 1997.

BOSI, Alfredo. A arqueologia do Estado-providência. In: A dialética da colonização. São Paulo: Companhia das Letras, 1992. p. 273-307.

CHAVES, Luís Guilherme Bacelar. VIANA, Oliveira. Dicionário Histórico-Biográfico Brasileiro. Rio de Janeiro: Fundação Getúlio Vargas/CPDOC. CD-Room.

COUTINHO, Amélia; FALCÃO, Valdemar. Dicionário Histórico-Biográfico Brasileiro. Rio de Janeiro: Fundação Getúlio Vargas/CPDOC. CD-Room.

D'ARAÚJO, Maria Celina. Sindicatos, carisma e poder: O PTB de 1945-65. Rio de Janeiro: Fundação Getúlio Vargas Editora, 1996.

DELGADO, Lucília de Almeida Neves. PTB: Do getulismo ao reformismo, 1945-1964. São Paulo: Marco Zero, 1989.

FAUSTO, Boris. O pensamento nacionalista autoritário. Rio de Janeiro: Jorge Zahar, 2001. 
. Estado, classe trabalhadora e burguesia industrial, (1920/1945): uma revisão. In: Novos Estudos Cebrap, São Paulo, v. 20, p. 06-37, 1988.

. Trabalho urbano e conflito industrial - 1890-1920. São Paulo: Difel, 1976.

FONSECA, Pedro Cézar Dutra. Instituições e política econômica: crise e crescimento no Brasil da década de 1930. In: BASTOS, Pedro Paulo Zahluth; FONSECA, Pedro Cézar Dutra (Orgs.). A Era Vargas. Desenvolvimento, economia e sociedade. São Paulo: Editora UNESP, 2012. p. 159-178.

FRENCH, John D. Afogados em leis: A CLT e a cultura política dos trabalhadores brasileiros. São Paulo: Fundação Perseu Abramo, 2001.

GOMES, Ângela de Castro; SILVA, Fernando Teixeira da (Org.). A Justiça do Trabalho e sua História. Campinas: Editora Unicamp, 2013.

. Autoritarismo e corporativismo no Brasil: intelectuais e a construção do mito Vargas. In: PINTO, António Costa; MARTINHO, Francisco Carlos Palomanes (Orgs.). O corporativismo em português. Estado, política e sociedade no salazarismo e no varguismo. Rio de Janeiro: Civilização Brasileira, 2007. p. 79-207.

O Ministério da Revolução de 1964: previdência e assistência sociais no governo Geisel. In: CASTRO, Celso; D'ARAÚJO, Maria Celina (Orgs.). Dossiê Geisel. Rio de Janeiro: Editora FGV, 2002a. 121-148.

. A escola republicana: entre luzes e sombras. In: GOMES, Ângela de Castro; PANDOLFI, Dulce Chaves; ALBERTI, Verena (Orgs.). A República no Brasil. Rio de Janeiro: Nova Fronteira: CPDOC, 2002b. p. 384-437. 2000.

. (Org.). Capanema: o ministro e seu ministério. Rio de Janeiro: Editora FGV,

. Ideologia e trabalho no Estado Novo. In: PANDOLFI, Dulce (Org.). Repensando o Estado Novo. Rio de Janeiro: Editora FGV, 1999. p. 53-72.

. A invenção do trabalhismo. Rio de Janeiro: Relume Dumará, 1994.

República, trabalho e cidadania. Rio de Janeiro: Fundação Getúlio Vargas/ $\overline{\mathrm{CPDOC}}, 1991$.

. Burguesia e trabalho: Política e legislação social no Brasil, 1917-1937. Rio de Janeiro: Campus, 1979. p. 199-252.

HIPÓLITO, Lúcia. PSD: de raposas e reformistas. Rio de Janeiro: Paz e Terra, 1984.

KORNIS, Mônica. VIANA, Segadas. Dicionário Histórico-Biográfico Brasileiro. Rio de Janeiro: Fundação Getúlio Vargas/CPDOC. CD-Room.

LAMOUNIER, Bolívar. Formação de um pensamento político autoritário na Primeira República: uma interpretação. In: FAUSTO, Boris (Org.). História geral da civilização brasileira. São Paulo: Difel, 1985. Tomo III. Vol. 2. p. 343-374.

MARCANTE, Carolina. As centrais sindicais e o neocorporativismo à brasileira. Revista Estudos Políticos. Laboratório de Estudos Hum(e)anos (UFF); Núcleo de Estudos em Teoria Política (UFRJ). Rio de Janeiro, v. 5, n. 1, p. 267-287, dez. 2014.

MARTINHO, Francisco Carlos Palomanes. O imigrante português no mundo do trabalho, nos movimentos sociais e nas organizações sociais do Rio. In: LESSA, Carlos (Org.). Os Lusiadas na aventura do Rio moderno. Rio de Janeiro: Record/FAPERJ, 2002. p. 199-240. 
MARTINHO, Francisco Carlos Palomanes; BESKOW, Gabriela Carames. Trabalhismo em Gestação: O Ministério do Trabalho no Período Marcondes Filho (1941-1945). Trabalho apresentado no VII Congresso Luso-Afro-Brasileiro de Ciências Sociais. As linguagens da lusofonoia. Universidade Cândido Mendes/IUPERJ, 2002. Disponível em: <www.iuperj.br>. Acesso em: 15 nov. 2015.

MAYER, Jorge Miguel; MARCONDES FILHO. Dicionário Histórico-Biográfico Brasileiro. Rio de Janeiro: Fundação Getúlio Vargas/CPDOC. CD-Room.

MENDONÇA, Joseli Maria Nunes. Evaristo de Moraes, tribuno da República. Campinas: Editora Unicamp, 2007.

MOREIRA, Regina da Luz; SALGADO FILHO, Joaquim Pedro. Dicionário Histórico-Biográfico Brasileiro. Rio de Janeiro: Fundação Getúlio Vargas/CPDOC. CD-Room.

PANDOLFI, Dulce Chaves. Pernambuco de Agamenon Magalhães. Recife: Massangana, 1984.

PANTOJA, Sílvia. MAGAlHÃES, Agamenon. Dicionário Histórico-Biográfico Brasileiro. Rio de Janeiro: Fundação Getúlio Vargas/CPDOC. CD-Room.

PINHEIRO, Paulo Sérgio. Classes médias urbanas: formação, natureza e intervenção na vida política. In: FAUSTO, Boris (Org.). História geral da civilização brasileira. São Paulo: Difel, 1985. Tomo III. Vol. 2. p. 7-37.

PINTO, António Costa. Elites, partido único e decisão política nas ditaduras da época do fascismo. Penélope, Lisboa, n. 26, p. 161-186, 2002.

RODRIGUES, Leôncio Martins. Sindicalismo e classe operária - 1930-1964. In: FAUSTO, Boris (Org.). História Geral da Civilização Brasileira. São Paulo: Difel, 1986. Tomo III: O Brasil Republicano. Vol. 3: Sociedade e Política (1930-1964). p. 532-533.

SIRINELLI, Jean-François. Le hasard ou la necessite? Une histoire em chantier. L'histoire des intellectuels. Vingtième siècle, Revue d'istoire, Paris, v. 9, p. 97-108, jan.-mars 1986.

SOUZA, Maria do Carmo Campello de. Estado e partidos politicos no Brasil (1930 a 1964). São Paulo: Alfa-Ômega, 1983.

TRINDADE, Hélgio. Integralismo: Teoria e práxis política nos anos 30. In: Boris Fausto (org.). História Geral da Civilização Brasileira. São Paulo: Difel, 1986. Tomo III: O Brasil Republicano. Vol. 3: Sociedade e Política (1930-1964). p. 297-335.

VENÂNCIO, Giselle. Oliveira Vianna entre o Espelho e a Máscara. Belo Horizonte: Autêntica, 2015.

VIANNA, Luiz Werneck. Liberalismo e sindicato no Brasil. Rio de Janeiro: Paz e Terra, 1978.

. O Estado Novo e a "ampliação" autoritária da República. In: CARVALHO, Maria Alice Rezende de (Org.). República no Catete. Rio de Janeiro: Museu da República, 2001.

VIANNA, Marly de Almeida Gomes. Revolucionários de 35: sonho e realidade. São Paulo: Companhia das Letras, 1992.

VIEIRA, Evaldo. Autoritarismo e corporativismo no Brasil: Oliveira Viana \& Companhia. São Paulo: Cortez, 1981. p. 103-133. 


\title{
Fontes:
}

COLLOR, Lindolpho. Lindolpho Collor e a questão social: coletânea de artigos escritos no período de 1919-1941. [s/ed; s/d.].

VIANA, Francisco José de Oliveira. O idealismo da Constituição. Rio de Janeiro: Terras de Sol, 1927.

Recebido: 23 de novembro de 2015

Aprovado: 21 de janeiro de 2016

\begin{abstract}
Autor/Author:
FRANCISCO CARlos PALOMANES MARTINHO <fcpmartinho@usp.br>

- Professor Livre-docente do Departamento de História da Universidade de São Paulo e pesquisador do CNPq (Conselho Nacional de Desenvolvimento Científico e Tecnológico). Desenvolve pesquisas sobre a História Política Contemporânea de Portugal no século XX, nomeadamente sobre a direita, a ditadura do Estado Novo e de seu processo de transição para a democracia. É autor, entre outros de A Bem da Nação: o Sindicalismo Português entre a Tradição e a Modernidade (1933-1945) (Civilização Brasileira, 2002) e organizador de A Vaga Corporativa: corporativismo e ditaduras na Europa e na América Latina (Imprensa de Ciências Sociais, 2016), O passado que não passa: a memória das ditaduras na Europa do Sul e na América Latina (Civilização Brasileira, 2013) e O corporativismo em português: Estado, politica e sociedade no Salazarismo e no Varguismo (Imprensa de Ciências Sociais, 2008 e Civilização Brasileira, 2007).

- Associate Professor in the Department of History at the Universidade de São Paulo and research fellow of CNPq (National Council for Scientific and Technological Development, Brazil). He develops his research on the Contemporary Political History of Portugal during the 20th century, addressing the rightwing politics, the Estado Novo dictatorship, and the process of transition to democracy. He is the author, among other Works, of A Bem da Nação: o Sindicalismo Português entre a Tradição e a Modernidade (1933-1945) (Civilização Brasileira, 2002) and organizer of A Vaga Corporativa: corporativismo e ditaduras na Europa e na América Latina (Imprensa de Ciências Sociais, 2016), O passado que não passa: a memória das ditaduras na Europa do Sul e na América Latina (Civilização Brasileira, 2013) and O corporativismo em português: Estado, política e sociedade no Salazarismo e no Varguismo (Imprensa de Ciências Sociais, 2008 e Civilização Brasileira, 2007).
\end{abstract}

